\title{
The Role of the Eosinophil-selective Chemokine, Eotaxin, in Allergic and Non-allergic Airways Inflammation
}

\author{
Dolores M Conroy, Alison A Humbles, Sara M Rankin, Roger T Palframan, \\ Paul D Collins, David A Griffiths-Johnson, Peter J Jose, Timothy J Williams ${ }^{+}$
}

Department of Applied Pharmacology, Imperial College School of Medicine, National Heart and Lung Institute, London SW3 6LY, U.K.

Blood eosinophilia and tissue infiltration by eosinophils are frequently observed in allergic inflammation and parasitic infections. This selective accumulation of eosinophils suggested the existence of endogenous eosinophil-selective chemoattractants. We have recently discovered a novel eosinophilselective chemoattractant which we called eotaxin in an animal model of allergic airways disease. Eotaxin is generated in both allergic and non-allergic bronchopulmonary inflammation. The early increase in eotaxin paralled eosinophil infiltration in the lung tissue in both models. An antibody to IL-5 suppressed lung eosinophilia, correlating with an inhibition of eosinophil release from bone marrow, without affecting eotaxin generation. This suggests that endogenous IL-5 is important for eosinophil migration but does not appear to be a stimulus for eotaxin production. Constitutive levels of eotaxin observed in guinea-pig lung may be responsible for the basal lung eosinophilia observed in this species.

Allergen-induced eotaxin was present mainly in the epithelium and alveolar macrophages, as detected by immunostaining. In contrast there was no upregulation of eotaxin by the epithelial cells following the injection of Sephadex beads and the alveolar macrophage and mononuclear cells surrounding the granuloma were the predominant positive staining cells.

Eotaxin and related chemokines acting through the CCR 3 receptor may play a major role in eosinophil recruitment in allergic inflammation and parasitic diseases and thus offer an attractive target for therapeutic intervention.

Key words: eotaxin - eosinophil - airways - inflammation

\section{EOSINOPHILS IN INFLAMMATION}

Eosinophils are granule-containing leukocytes that differentiate from stem cell precursors in the bone marrow, circulate in the blood, and then enter peripheral tissues where they can survive for at least two weeks (Spry 1971). Increased levels of circulating and tissue eosinophils are characteristic features of a number of pathological conditions e.g parasitic infections, local allergic reactions such as asthma, rhinitis and eczema, and hypereosinophilic syndrome. Eosinophils are considered to be important effector cells for killing certain parasitic helminths (Butterworth 1984) but can also cause direct damage to healthy mammalian tissues by a variety of mechanisms including the release of preformed toxic cationic proteins and oxygen radi-

This research was supported by Wellcome Trust, National Asthma Campaign, Allen \& Hanburys and the European Commission.

${ }^{+}$Corresponding author. Fax: +44-171-351.8270.

Received 3 September 1997

Accepted 30 September 1997 cals (Gleich et al. 1988). Eosinophils synthesise and release lipid-derived mediators which stimulate responses in tissues such as smooth muscle contraction or microvascular leakage (Rabe et al. 1994). In addition, eosinophils produce cytokines such as interleukin (IL)-3, IL-5 and granulocytemacrophage colony stimulating factor (GM-CSF) that contribute to their proinflammatory functions. The cationic proteins, major basic protein (MBP), eosinophil peroxidase (EPO) and eosinophil cationic protein (ECP) are toxic to airway epithelium and may be deposited over large areas of the bronchial epithelial lining in patients with asthma (Filley et al. 1982, Venge et al. 1988). MBP and ECP have been detected in serum from asthmatics, a consequence of eosinophil degranulation (Dahl et al. 1978, Wassom et al. 1981). In asthmatics, the number of eosinophils in the bronchoalveolar lavage fluid and airway mucosa has been shown to correlate with the degree of lung dysfunction (Kay et al. 1986). In experimental studies in allergic models of airway inflammation the suppression of eosinophil accumulation in the lung by interference with cellular adhesion mechanisms inhibits bronchial hyperresponsiveness (Gundel et al. 1991). Similarly neutralisation of MBP inhibits allergen- 
induced hyperreactivity in the guinea pig (Lefort et al. 1996).

\section{MECHANISMS OF EOSINOPHIL RECRUITMENT}

The mechanisms that regulate eosinophil recruitment and activation at sites of inflammation are areas of active investigation. It has now become clear that extravascular recruitment and activation of leukocytes are the end result of a complex network of interactions among cellular adhesion molecules, cytokines, and other inflammatory mediators (Springer 1994, Carlos \& Harlan 1994). The initial step in extravasation is rolling of leukocytes along the venule wall, resulting from a loose, transient adhesion mediated largely by the selectin family of adhesion molecules. Subsequent to rolling, a firmer adhesion between leukocytes and endothelium is established by binding of integrins on the leukocytes to counter ligands of the immunoglobulin superfamily on the endothelium. Eosinophils express several adhesion molecules such as $\beta 1$ and $\beta 2$ integrins that participate in their interactions with the vascular endothelium. Chemoattractants may enhance the adhesion of leukocytes to the endothelium by upregulation and activation of the integrins. Although the binding of leukocyte integrins to endothelial ligands such as intercellular adhesion molecule-1 (ICAM-1) and vascular cell adhesion molecule-1 (VCAM-1) establishes a firm contact between the two cells, this interaction is not permanent. The leukocyte soon crawls through a junctional space in the endothelium, which it traverses by a mechanism that involves the homotypic binding between plateletendothelial cell adhesion molecule-1 (PECAM-1) on leukocytes and the endothelium. The leukocyte is guided through the tissue to its final destination by gradients of chemoattractants, which are produced at the site of inflammation and diffuse towards the vasculature. Ultimately, the leukocyte arrives at the inflammatory lesion, where it becomes activated to carry out its function. Various chemoattractants active on eosinophils including leukotriene (LT) $\mathrm{B}_{4}$, platelet activating factor (PAF) and C5a have been identified as mediators of eosinophil trafficking. These molecules also induce the migration of other cell types and their relative importance in diseases and in experimental models of inflammation is unclear. The observation that a selective accumulation of eosinophils occurs in allergic reactions, as well as in parasitic infections, has led several investigators to search for factors that are chemotactic specifically for eosinophils. In the last decade a new family of chemotactic cytokines called chemokines have attracted much attention because of their restricted target cell specificity.

\section{CHEMOKINES}

Chemokines are 8-10kDa heparin-binding proteins that mediate a range of pro-inflammatory effects on leukocytes, such as chemotaxis, degranulation, synthesis of lipid mediators, and integrin activation (Miller \& Krangel 1992, Baggiolini \& Dahinden 1994). Chemokines are defined by a common structural motif, consisting of four conserved cysteine residues that form two characteristic intramolecular disulfide bridges (Schall \& Bacon 1994). The chemokines can be divided into two main groups based on the position of the $\mathrm{N}$ terminal pairs of conserved cysteine residues. In the $\alpha$ or $\mathrm{C}-\mathrm{X}-\mathrm{C}$ chemokines, these residues are separated by an intervening amino acid. In the $\beta$ or C-C chemokines, they are immediately adjacent to each other. Recently a chemoattractant for lymphocytes that contains only two of the four cysteine residues has been identified and called lymphotactin. The two main chemokine families differ in their ability to stimulate different kinds of effector cells. The C-X-C family of chemokines containing an ELR motif in the N-terminal region, such as interleukin-8 (IL-8), neutrophil activating protein (NAP) 2 and melanoma growth-stimulatory activity (MGSA), are primarily chemoattractants for neutrophils. The non-ELR C-X-C chemokines which include platelet factor 4 (PF4) and interferon $\gamma$-inducible protein (IP-10) fail to attract neutrophils and are angiostatic. Chemokines of the C-C family such as RANTES (regulated upon activation normal $\mathrm{T}$ cell expressed and secreted), macrophage inhibitory protein (MIP)- $1 \alpha$, MIP-1 $\beta$, macrophage chemoattractant protein (MCP) 1,2 , 3,4 , and 5, chemoattract and activate monocytes, dendritic cells, $\mathrm{T}$ and $\mathrm{B}$ lymphocytes, basophils and eosinophils. Eotaxin is a C-C chemokine with a more restricted range of target cells.

\section{EOTAXIN IN ANIMAL MODELS OF ALLERGIC AIR-} WAY INFLAMMATION

Eotaxin was discovered as an eosinophil-selective chemoattractant in the bronchoalveolar lavage (BAL) fluid taken following allergen challenge of actively sensitised guinea pigs (GriffithsJohnson et al. 1993, Jose et al. 1994a). BAL fluid taken from sensitised guinea pigs at intervals after allergen challenge, when injected intradermally into naive guinea pigs, induced an accumulation of ${ }^{111}$ In-eosinophils. Eosinophil chemoattractant activity in BAL fluid was detected at $30 \mathrm{~min}$ following allergen challenge peaking from 3-6 hr and declining to low levels by $24 \mathrm{hr}$.

The chemoattractant activity in BAL fluid was purified using cation exchange, molecular sizing and reverse phase chromatography techniques in conjunction with skin bioassays to determine the active fractions. At the final purification step of reverse 
phase high pressure liquid chromatography eosinophil chemoattractant activity was present in three fractions, 51, 52 and 54 which were associated with discreet peaks of protein absorbance (Fig. 1) Selectivity for eosinophils was shown by lack of a significant accumulation of ${ }^{111}$ In-neutrophils in the skin assays. SDS-PAGE analysis revealed a single protein band in each of fractions 51,52 and 54 although the protein in each fraction appeared to be of a different size. Microsequence analysis revealed a novel protein of 73 amino acids which exhibits similarity to other known eosinophil-activating C-C chemokines (Fig. 2). This protein, which we called eotaxin, has sequence similarity of 51\%,53\% and $54 \%$, with human MCP-3, MCP-1 and MCP-2 respectively, $44 \%$ with guinea pig MCP-1, $31 \%$ with human MIP- $1 \alpha$ and $26 \%$ with human RANTES. Guinea pig eotaxin elevated intracellular $\mathrm{Ca}^{2+} \mathrm{lev}-$ els in guinea pig and human eosinophils as well as inducing eosinophil aggregation (Griffiths-Johnson et al. 1993, Jose et al. 1994a).

Using PCR with primers based on the protein sequence of guinea-pig eotaxin to obtain probes, guinea-pig lung cDNA libraries were screened and the full length eotaxin cDNA was cloned (Jose et al. 1994a, Rothenberg et al. 1995b). This cDNA encoded a 96 amino acid protein with a 23 amino acid leader sequence. A murine eotaxin gene has been identified which has 63\% homology with guinea pig eotaxin at the protein level (Rothenberg et al. 1995b).

Constitutive and allergen-induced expression of eotaxin mRNA has been shown in guinea pig lung (Jose et al. 1994b, Rothenberg et al. 1995a). The constitutive expression of eotaxin in the lungs
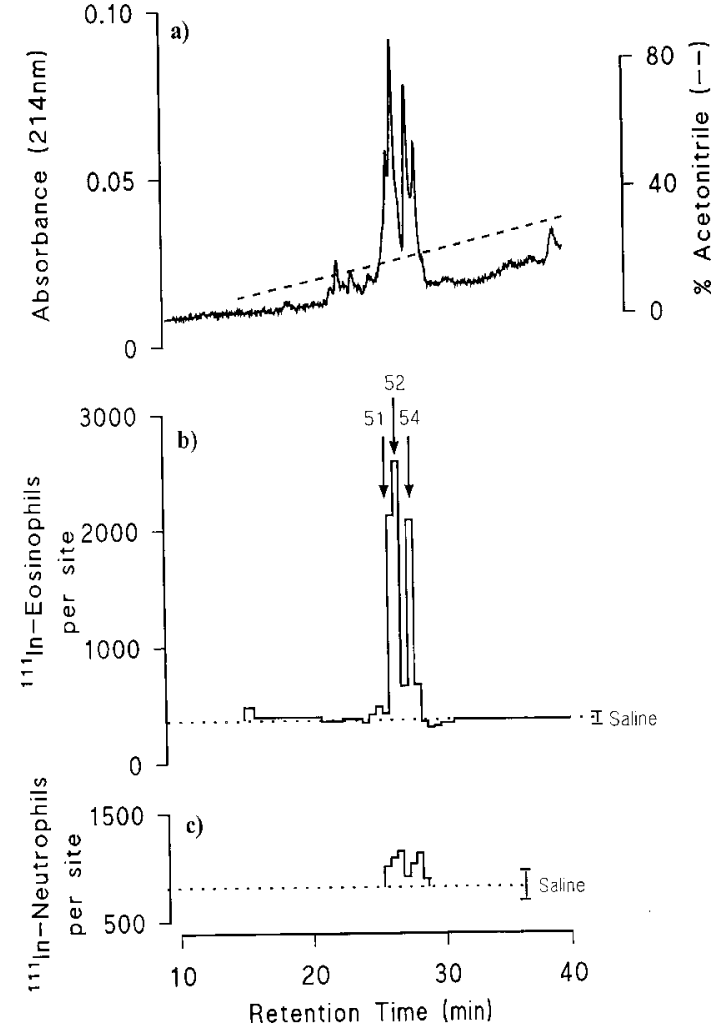

Fig. 1: purification of eotaxin from BAL fluid. a) Final reversed phase HPLC profile showing absorbance at $214 \mathrm{~nm}$ and the acetonitrile gradient. b) Eosinophil chemoattractant activity measured in skin was seen as two peaks, fractions $51+52$ and fraction 54, which corresponded to discreet peaks of absorbance. c) No significant neutrophil chemoattractant activity was detected in these fractions. Reproduced from The Journal of Experimental Medicine (1994) 179: 881-887 by copyright permission of The Rockerfeller University Press.

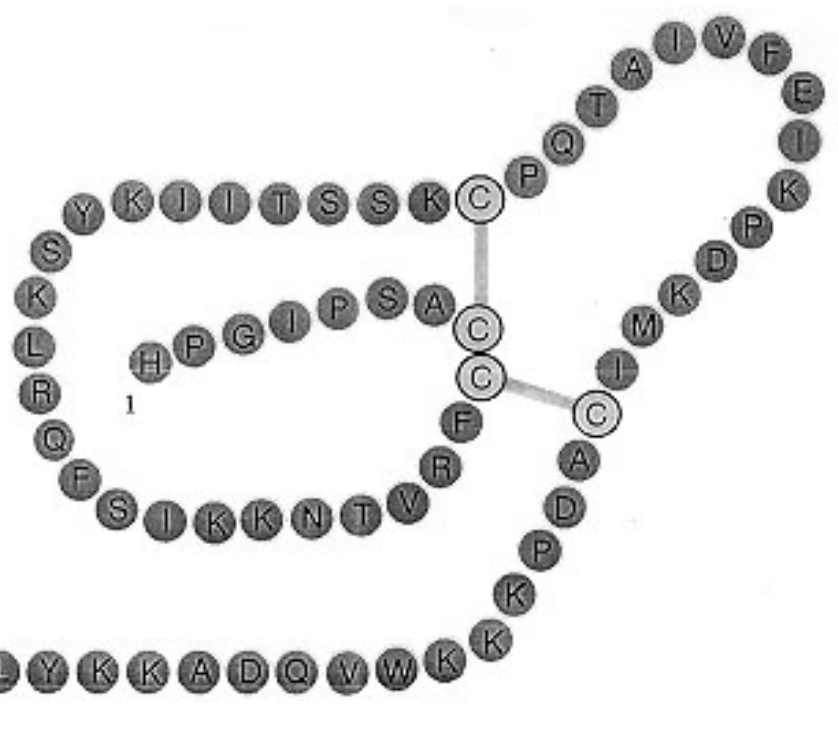

Fig. 2: amino acid sequence of guinea-pig eotaxin. 
of naive guinea pigs suggests that this chemokine may regulate basal eosinophil tissue homing in this species. After allergen challenge, eotaxin gene expression in the lung is further increased and parallels the peak changes in eotaxin protein that we have observed in BAL fluid (Humbles et al. 1997). The pronounced lung eosinophilia which peaks $3 \mathrm{hr}$ after antigen challenge in a murine model of asthma was associated with an increase in eotaxin expression in the lung (Gonzalo et al. 1996a). A neutralising antibody to eotaxin induced a significant inhibition of eosinophil infiltration following allergen challenge in the above model (Gonzalo et al. 1996b). Mature CD4 cells are absolutely necessary for allergen-induced eosinophil accumulation since lung eosinophilia was prevented in CD4deficient mice (Gonzalo et al. 1996b). The mechanism by which T-cells assist in the recruitment of eosinophils to the lung in this model is not well understood. Pretreatment with an anti-CD3 antibody significantly inhibited eotaxin mRNA expression in sensitised mice after airway challenge and this was associated with a significant reduction in pulmonary eosinophilia (MacLean et al. 1996). The correlation of reduced eotaxin mRNA expression with reduced lung eosinophilia in anti-CD3-treated mice suggests that eotaxin may be a key regulator of eosinophilia and an important eosinophil chemoattractant. The inhibition of allergen-induced eotaxin mRNA expression by anti-CD3 may result from the elimination of T-cell-derived factors that induce eotaxin mRNA expression in lung cells. Interestingly, MIP- $1 \alpha$ and RANTES, which are also eosinophil chemoattractants, were induced by anti-CD3 treatment in allergen-challenged sensitised mice.

Using targeted gene disruption to create mice with a genetic deficiency in eotaxin it was shown that eotaxin enhanced the magnitude of early eosinophil recruitment observed at $18 \mathrm{hr}$ following allergen challenge (Rothenberg et al. 1997). Eotaxin knockout mice also showed a reduced peripheral blood eosinophil count which was not due to an inhibition of eosinophil hematopoiesis. In addition, the early recruitment of eosinophils to the cornea during experimental keratitis induced by the helminth Onchocerca volvulus was shown to be mediated by eotaxin (Rothenberg et al. 1997).

\section{HUMAN EOTAXIN}

Using probes based on the guinea pig and mouse clones, human homologues of eotaxin have now been cloned (Ponath et al. 1996b, GarciaZepeda et al. 1996, Kitaura et al. 1996). Human eotaxin is an $8.4 \mathrm{kDa}, 74$ amino acid polypeptide which shows highest amino acid sequence identity to human MCP-3 (69\%), MCP-4 (60\%),
RANTES (34\%), guinea pig eotaxin (62\%) and mouse eotaxin $(59 \%)$. Human eotaxin induces chemotaxis of human eosinophils, but not of neutrophils, lymphocyes or monocytes. In addition, eotaxin was shown to induce the respiratory burst of eosinophils, upregulate the integrin CD11b on eosinophils (Elsner et al. 1996, Tenscher et al. 1996) and stimulate the adhesion of eosinophils to human lung microvascular endothelial cells (Burke-Gaffney \& Hellewell 1996). Studies in the rhesus monkey showed that eotaxin was effective at recruiting eosinophils locally in the skin (Ponath et al. 1996b).

Constitutive human eotaxin mRNA expression was observed in many normal human tissues including small bowel and colon, and to a lesser extent in heart, kidney, spleen, liver, thymus and lung (Garcia-Zepeda et al. 1996). The presence of constitutive eotaxin in the small bowel and colon may reflect the role of eotaxin in baseline eosinophil homing, where the cell plays an important role in host defence against helminth pathogens. Eotaxin mRNA is markedly upregulated in the lesions of patients with inflammatory bowel disease and may explain the mechanism of eosinophil recruitment in diseases such as ulcerative colitis and Crohn's disease (Garcia-Zepeda et al. 1996). Immunohistochemistry on human nasal polyps with an antieotaxin monoclonal antibody showed that the respiratory epithelium, as well as certain leukocytes, were intensely immunoreactive and eosinophil infiltration occured at the sites of eotaxin upregulation (Ponath et al. 1996b). We have also recently detected eotaxin protein by ELISA in nasal polyp homogenates (D Conroy et al. unpublished observations).

Human eotaxin mRNA is expressed by human umbilical cord endothelial cells (HUVECs), respiratory epithelial cells (BEAS-2B cells), U937 monocytic cells and colonic epithelial cells (Caco2) following stimulation with cytokines such as TNF- $\alpha$ and IFN- $\gamma$ (Garcia-Zepeda et al. 1996). Cells known to express detectable levels of eotaxin

TABLE

C-C chemokine receptors

\begin{tabular}{lccccc}
\hline Ligand & CCR1 & CCR2 & CCR3 & CCR4 & CCR5 \\
\hline RANTES & + & & + & + & + \\
MIP-1 $\alpha$ & + & & & + & + \\
MIP-1ß & & & & & + \\
MCP-1 & & + & & + & \\
MCP-2 & & & + & & \\
MCP-3 & + & + & + & & \\
MCP-4 & & + & + & & \\
Eotaxin & & & + & & \\
\hline
\end{tabular}


mRNA include pseudostratified ciliated columnar epithelium, endothelium, lymphocytes, macrophages, eosinophils and dermal fibroblasts (Ponath et al. 1996b, Gonzalo et al. 1996a, Bartels et al. 1996). Cytokine-induced eotaxin mRNA expression and protein production in A549 cells, a human respiratory epithelial cell line, were inhibited by dexamethasone and thus defines a novel mechanism of glucocorticoid action which may be relevant to asthma (Lilly et al. 1997).

\section{CHEMOKINE RECEPTORS}

Identification of $\mathrm{C}-\mathrm{C}$ chemokines has contributed greatly to our understanding of eosinophil biology and information regarding their receptors is now emerging. To date, six human $\mathrm{C}-\mathrm{C}$ receptors have been cloned and characterized (Table). They are all seven transmembrane G-protein coupled glycoproteins and have $45-75 \%$ amino acid sequence identity.

CCR1 was the first identified C-C chemokine receptor and is expressed on monocytes, mature and immature myeloid cells, B lymphocytes and eosinophils. CCR1 binds MIP-1 $\alpha$, RANTES and MCP-3 with high affinity and MIP- $1 \beta$ and MCP-1 with lower affinity. CCR2A and CCR2B, spliced variants of a single gene, specifically bind MCP-1 with high affinity and MCP-3 with low affinity. These two receptors are expressed on monocytes but not on neutrophils or eosinophils. CCR4 is expressed on T cells and IL-5 primed basophils and mediates the biological effects of RANTES, MCP-1 and MIP-1 $\alpha$. CCR5 is expressed in primary adherent monocytes and binds MIP- $1 \alpha$, MIP$1 \beta$ and RANTES.

The receptor mediating the biological effects of eotaxin is CCR3 which is expressed in high numbers on eosinophils (Daugherty et al. 1996, Ponath et al. 1996a, Kitaura et al. 1996). Expression of CCR3 has also been shown on basophils, mast cells, some T-cell clones, as well as tissue macrophages. CCR3 is also responsible for mediating the biological effects of other eosinophil active chemokines such as RANTES, MCP-3 and MCP-4. Several features of CCR3 distinguish it from the other $\mathrm{C}-\mathrm{C}$ receptors. It is expressed at high levels on eosinophils, 40,000-400,000 receptors per cell, compared to CCR1 and CCR2 which are expressed on monocytes and $T$ cells usually at $<3,000$ receptors per cell. CCR3 is the only eotaxin receptor identified to date. Therefore an interaction between eotaxin and CCR3 could lead to selective eosinophil recruitment to sites of allergic inflammation or parasitic disease.

Recently a fully antagonistic monoclonal antibody for human CCR3 was shown to completely block the binding and signaling of the known CCR3 ligands such as eotaxin, RANTES, MCP-2, MCP3 and MCP-4 (Heath et al. 1997). In addition $>95 \%$ of the responses of eosinophils from allergic and eosinophilic donors to the known CCR3 ligands were mediated through CCR3. To date there is no information available to determine whether disrupting the eotaxin-CCR3 interaction prevents eosinophil-specific tissue infiltration. CCR1, although expressed in much lower numbers on eosinophils, can also bind RANTES and MCP-3 which are also eosinophil chemoattractants and thus may contribute to eosinophil accumulation. Similar functional studies using neutralising anti CCR1 monoclonal antibodies will be important to define a role, if any, for CCR1 on eosinophils.

KINETICS OF EOTAXIN GENERATION AND ITS ASSOCIATION WITH EOSINOPHIL ACCUMULATION IN ALLERGIC AIRWAYS INFLAMMATION IN THE GUINEA PIG

Allergen challenge of sensitised animals has been shown to be associated with an increased expression of eotaxin mRNA in the lung of both guinea pigs and mice (Jose et al. 1994b, Rothenberg et al. 1995a, b, Gonzalo et al. 1996a). We have examined the kinetics of eosinophil infiltration and the association with levels of immunoreactive eotaxin, measured by RIA, in allergic and non-allergic bronchopulmonary inflammation in the guinea pig. We have also investigated the effects of dexamethasone and an anti-IL-5 antibody on eosinophil infiltration and eotaxin generation in both models.

To induce allergic airways inflammation guinea pigs were sensitised with an i.p. injection of ovalbumin on day 1 and 15 . On day 28 , sensitised animals were exposed to aerosolised ovalbumin and at different times after allergen challenge animals

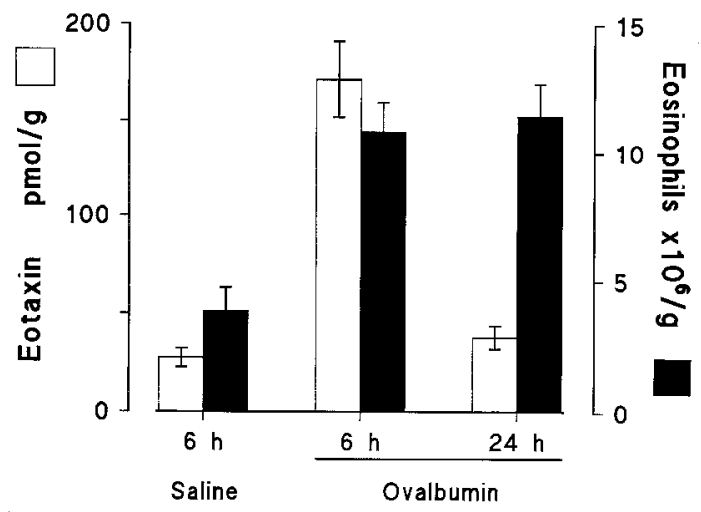

Fig. 3: lung tissue eotaxin generation and eosinophil accumulation. Sensitized guinea pigs were challenged with aerosolised ovalbumin or saline and lung eotaxin and eosinophils measured at 6 and $24 \mathrm{hr}$. 
were killed and BAL performed. Eosinophils in the BAL fluid were counted and immunoreactive eotaxin in lung tissue and BAL fluid measured by RIA. Eosinophils in lung tissue were quantitated as eosinophil peroxidase (EPO) activity as previously described (Das et al. 1995).

There was a good correlation between the appearance of eotaxin and eosinophil accumulation in the lung tissue of allergen-challenged guinea pigs. Levels of eotaxin peaked at $6 \mathrm{hr}$ post challenge, decreased at $12 \mathrm{hr}$ and returned to basal levels by $24 \mathrm{hr}$. Eosinophils in lung tissue were significantly elevated at $6 \mathrm{hr}$ and remained high up to $24 \mathrm{hr}$, probably influenced by factors increasing eosinophil survival such as IL-5 (Fig. 3). In contrast, there was a dissociation between eosinophil accumulation and eotaxin generation when measured in BAL fluid. Eotaxin levels peaked at $6 \mathrm{hr}$ post challenge at a time when eosinophil numbers were not significantly elevated, but fell to low levels at $12 \mathrm{hr}$ when eosinophil numbers began to increase. Thus, eosinophil recruitment through the vascular endothelium appears to be rapid, whereas extensive traffic through the airway epithelium is considerably delayed. Eotaxin generated in the airway wall would be expected to pass from and through the airway epithelium into the lumen and indeed a similar time course of eotaxin was observed in BAL as in lung tissue. There appears to be a faster metabolism or clearance of eotaxin from the lung tissue than from the lumen. Thus while eotaxin is being generated in lung tissue, a gradient between the tissue and microvessel lumen will facilitate eosinophil traffic across the vascular endothelium. However, during active chemokine secretion, the eotaxin concentration in the fluid lining the airways will be lower than in the tissue, the direction of the gradient inhibiting migration into the lumen. Subsequently, when eotaxin secretion ceases, clearance and metabolism may reverse the gradient across the epithelium, thus facilitating migration of eosinophils into the airway lumen over the $12-24 \mathrm{hr}$ period.

The immunoreactive eotaxin in BAL fluid was biologically active and induced the accumulation of eosinophils when injected intradermally. As shown for eotaxin mRNA (Jose et al. 1994b, Rothenberg et al. 1995b) there was a low but significant amount of eotaxin protein in the fluid from naive/saline- and sensitised/saline-challenged animals which was significantly elevated following allergen challenge of sensitised animals. A polyclonal anti-eotaxin IgG neutralised both the constitutive and allergen-induced eosinophil chemoattractant activity in BAL fluid (Humbles et al. 1997).
MODULATION OF EOSINOPHIL TRAFFICKING AND EOTAXIN GENERATION BY DEXAMETHASONE AND AN ANTI-IL-5 ANTIBODY

Dexamethasone administered i.p. prior to ovalbumin challenge markedly inhibited eosinophil accumulation in lung tissue and BAL fluid but did not affect eotaxin generation, showing that dexamethasone suppresses eosinophil accumulation in this model by some mechanism independent of eotaxin release. Eosinophils themselves are unlikely to be a source of eotaxin over the time period studied since marked suppression of eosinophil accumulation had no detectable effect on eotaxin generation.

Pretreatment of animals with TRFK-5, a neutralising monoclonal antibody to IL-5, significantly suppressed allergen-induced eosinophil accumulation. TRFK-5 had no significant effect on the numbers of mononuclear cells or neutrophils in BAL fluid. TRFK-5 had no effect on eotaxin generation showing that IL-5 does not appear to regulate eotaxin production.

\section{MOBILISATION OF EOSINOPHILS FROM THE BONE MARROW TO THE LUNG IN RESPONSE TO ALLERGEN CHALLENGE}

Allergen challenge of sensitised guinea pigs resulted in a rapid and progressive reduction in bone marrow eosinophils beginning at $1 \mathrm{hr}$ with a significant increase in peripheral blood eosinophils observed at $3 \mathrm{hr}$. This release of eosinophils from the bone marrow appears to be mediated by IL- 5 since it was inhibited by TRFK-5. In addition, TRFK- 5 increased the retention of bone marrow eosinophils in saline-challenged animals suggesting that IL-5 regulates the basal release of eosinophils. Eosinophils mobilised from the bone marrow were rapidly recruited to the lung where the eosinophil numbers correlated with increased eotaxin levels at 3 and $6 \mathrm{hr}$. The speed of eosinophil recruitment into lung tissue contrasts with their slow migration into the airway lumen as evidenced by their late appearance in BAL fluid despite an early increase in eotaxin levels in BAL fluid.

The results from the allergen model of airways inflammation in the guinea pig suggests that allergen stimulates the release of IL-5 and eotaxin. IL5 is carried by the blood to the bone marrow where it mobilises eosinophils into the circulation. Eotaxin then has the role of recruiting eosinophils from the microvasculature to the lung tissue. We have previously shown that intravenously injected IL-5 induces a rapid release of bone marrow eosinophils which results in a 13 fold increase in peripheral blood eosinophils. This results in a marked increase in eosinophil recruitment in response to intradermal eotaxin (Collins et al. 1995). 
EOTAXIN GENERATION AND EOSINOPHIL ACCUMULATION IN A MODEL OF NON-ALLERGIC AIRWAYS INFLAMMATION IN THE GUINEA PIG

A non-allergic airways inflammation in guinea pigs was induced following the intravenous injection of Sephadex G50 beads. This procedure has previously been shown to induce a marked eosinophil infiltration in guinea pig lung associated with an increase in bronchial hyperresponsiveness (Francischi et al. 1993). Eosinophils and eotaxin in lung tissue and BAL fluid were measured as described above for the allergic airways model.

Sephadex beads induced a significant increase in eosinophil numbers in lung tissue at $3 \mathrm{hr}$, which reached a peak at $12 \mathrm{hr}$ and remained significantly elevated at $48 \mathrm{hr}$ when compared to saline-injected animals. These kinetics of eosinophil accumulation correlated well with the levels of immunoreactive eotaxin measured in lung tissue. As has been observed above for the allergic airways model there appears to be a dissociation between eotaxin production and eosinophil infiltration into BAL fluid. Immunoreactive eotaxin was significantly elevated at $3 \mathrm{hr}$ and reached a peak at $12 \mathrm{hr}$ while eosinophil infiltration was only significantly elevated at $12 \mathrm{hr}$.

A significant increase in eosinophil chemoattractant activity in BAL fluid, measured as ${ }^{111}$ In-eosinophils accumulation, was observed at 3, 6, 12 and $24 \mathrm{hr}$ after Sephadex beads. This chemoattractant activity correlated closely with immunoreactive eotaxin measured in BAL fluid and was completely inhibited with a neutralising polyclonal anti-eotaxin IgG.

When administered in vivo the anti-eotaxin polyclonal $\mathrm{IgG}$ markedly attenuated eosinophil infiltration in both lung tissue and BAL fluid at 24 hr and had no effect on the Sephadex-induced mononuclear cell and neutrophil infiltration. Dexamethasone significantly attenuated both the Sephadex-induced eotaxin production and eosinophil infiltration in lung tissue and BAL fluid which is in contrast to the lack of effect of dexamethasone on eotaxin generation in the allergic model described above. TRFK-5 significantly inhibited eosinophil infiltration but did not affect the levels of eotaxin.

\section{CELLULAR LOCALIZATION OF EOTAXIN}

Immunohistochemical staining and in situ hybridisation show that there are multiple sources of eotaxin in guinea-pig airways which include airway epithelium, bronchial smooth muscle and chondrocytes. Following allergen challenge there is a marked upregulation of eotaxin gene expression and synthesis of this novel protein by airway epithelial cells and alveolar macrophages ( $\mathrm{Li}$ et al. 1997). In contrast, there was no upregulation of immunostaining for eotaxin in epithelial cells following the injection of Sephadex beads and the macrophage appeared to be the predominant positive-staining cell.

Thus, allergic and non-allergic stimuli can result in eosinophil accumulation mediated by the local production of the eosinophil-selective chemokine, eotaxin.

\section{CONCLUSIONS}

The selective accumulation of eosinophils at sites of allergic inflammation suggested the existence of endogenous eosinophil-specific chemoattractants. Various chemoattractants active on eosinophils such as $\mathrm{LTB}_{4}$, PAF and several chemokines (RANTES, MCP-3 and MIP- $1 \alpha$ ) have been identified as mediators of eosinophil trafficking but they also act on other cells. In addition, IL5 specifically regulates growth, differentiation and activation of eosinophils and provides an essential signal for the induction of eosinophilia during allergic inflammation. However, while IL-5 overproduction in transgenic mice causes a marked rise in blood eosinophils, it does not result in the accumulation of eosinophils in tissue (Dent et al. 1990).

In our laboratory we have purified and sequenced a novel eosinophil-selective chemoattractant, eotaxin, from the BAL fluid of allergen-challenged guinea pigs. Eotaxin is a 73 amino acid polypeptide belonging to the C-C family of chemokines. Recently we have shown that eotaxin is generated in a non-allergic model of airways inflammation, induced by the intravenous injection of Sephadex beads. In both models the kinetics of eotaxin generation parallels the accumulation of eosinophils in the lung tissue. Eotaxin in BAL fluid is biologically active as it induces an accumulation of eosinophils in guinea-pig skin in vivo which is inhibited by an anti-eotaxin antibody.

Eotaxin is a potent and selective chemoattractant for eosinophils in both in vivo and in vitro test systems. The potency and rapid action of eotaxin in inducing selective pulmonary and intradermal eosinophil accumulation suggests an integral role for this chemokine in eosinophil trafficking. In addition, eotaxin stimulates the release of reactive oxygen species, as well as inducing upregulation of integrins on eosinophils.

The high affinity of eotaxin for its receptor, CCR3, which is expressed in high numbers on eosinophils, and its selective activity suggests that eotaxin is an important chemokine for eosinophil function. There is recent evidence for CCR3 on basophils and mast cells which suggests that eotaxin may have additional functions in connec- 
tion with allergic reactions. The fact that other chemokines such as RANTES and some of the MCPs signal through CCR3 indicates that this receptor is a prime target for therapeutic intervention.

Currently, eotaxin and CCR3 show promise as molecules playing pivotal roles in eosinophil homing and tissue recruitment and are attractive therapeutic targets for the treatment of allergic diseases and parasitic infections.

\section{REFERENCES}

Baggiolini M, Dahinden CA 1994. CC chemokines in allergic inflammation. Immunol Today 15: 127-133.

Bartels J, Schluter C, Richter E, Noso N, Kulke R, Christophers E, Schroder J 1996. Human dermal fibroblasts express eotaxin: molecular cloning, mRNA expression, and identification of eotaxin sequence variants. Biochem Biophys Res Commun 225: 10451051.

Burke-Gaffney A, Hellewell PG 1996. Eotaxin stimulates eosinophil adhesion to human lung microvascular endothelial cells. Biochem Biophys Res Commun 227: 35-40.

Butterworth AE 1984. Cell-mediated damage to helminths. Adv Parasitol 23: 143-235.

Carlos TM, Harlan JM 1994. Leukocyte-endothelial adhesion molecules. Blood 84: 2068-2101.

Collins PD, Marleau S, Griffiths-Johnson DA, Jose PJ, Williams TJ 1995. Co-operation between interleukin5 and the chemokine,eotaxin, to induce eosinophil accumulation in vivo. J Exp Med 182: 1169-1174.

Dahl R, Venge P, Olsson I 1978. Variations of blood eosinophils and eosinophil cationic protein in serum in patients with bronchial asthma. Allergy 33: 211215.

Das AM, Williams TJ, Lobb RR, Nourshargh S 1995. Lung eosinophilia is dependent on IL-5, and the adhesion molecules CD18 and VLA-4 in a guinea-pig model. Immunology 84: 41-46.

Daugherty BL, Siciliano SJ, DeMartino J, Malkowitz L, Sirontino A, Springer MS 1996. Cloning, Expression and Characterization of the Human Eosinophil Eotaxin Receptor. J Exp Med 183: 2349-2354.

Dent LA, Strath M, Mellor AL, Sanderson CJ 1990. Eosinophilia in transgenic mice expressing interleukin 5. J Exp Med 172: 1425-1431.

Elsner J, Hochstetter R, Kimmig D, Kapp A 1996. Human eotaxin represents a potent activator of the respiratory burst of human eosinophils. Eur J Immunol 26: 1919-1925.

Filley WV, Holley KE, Kephart GM, Gleich GJ 1982. Identification by immunofluorescence of eosinophil granule major basic protein in lung tissues of patients with bronchial asthma. Lancet 2: 11-16.

Francischi JN, Conroy DM, Maghni K, Sirois P 1993. Inhibition by rapamycin of leukocyte migration and bronchial hyperreactivity induced by injection of Sephadex beads to guinea-pigs. Br J Pharmacol 110: 1381-1386.

Garcia-Zepeda EA, Rothenberg ME, Ownbey RT,
Celestin J, Leder P, Luster AD 1996. Human eotaxin is a specific chemoattractant for eosinophil cells and provides a new mechanism to explain tissue eosinophilia. Nature Medicine 2: 449-456.

Gleich GJ, Flavahan NA, Fujisawa T, Vanhoutte PM 1988. The eosinophil as a mediator of damage to respiratory epithelium: A model for bronchial hyperreactivity. J Allergy Clin Immunol 81: 776-781.

Gonzalo J, Jia G, Aguirre V, Friend D, Coyle AJ, Jenkins NA, Lin G, Katz H, Lichtman A, Copeland N, Kopf M, Gutierrez-Ramos J 1996a. Mouse eotaxin expression parallels eosinophil accumulation during lung allergic inflammation but it is not restricted to a Th2type response. Immunity 4: 1-14.

Gonzalo J, Lloyd CM, Kremer L, Finger E, Martinez-A C, Siegelman MH, Cybulsky MI, Gutierrez-Ramos J 1996b. Eosinophil recruitment to the lung in a murine model of allergic inflammation. The role of $\mathrm{T}$ cells, chemokines and adhesion receptors. J Clin Invest 98: 2332-2345.

Griffiths-Johnson DA, Collins PD, Rossi AG, Jose PJ, Williams TJ 1993. The chemokine, Eotaxin, activates guinea-pig eosinophils in vitro, and causes their accumulation into the lung in vivo. Biochem Biophys Res Commun 197: 1167-1172.

Gundel RH, Wegner CD, Torcellini CA, Clarke CC, Haynes N, Rothlein R, Smith CW, Letts LG 1991. Endothelial leukocyte adhesion molecule-1 mediates antigen-induced acute airway inflammation and late phase airway obstruction in monkeys. J Clin Invest 88: 1407-1411.

Heath H, Qin S, Rao P, Wu L, LaRosa G, Kassam N, Ponath PD, Mackay CR 1997. Chemokine receptor usage by human eosinophils. J Clin Invest 99: 178184.

Humbles AA, Conroy DM, Marleau S, Rankin SM, Palframan RT, Proudfoot AEI, Wells TNC, Li D, Jeffrey PK, Griffiths-Johnson DA, Williams TJ, Jose PJ 1997. Kinetics of eotaxin generation and its relationship to eosinophil accumulation in allergic airways disease: Analysis in a guinea pig model in vivo. $J$ Exp Med 186: 601-612.

Jose PJ, Griffiths-Johnson DA, Collins PD, Walsh DT, Moqbel R, Totty NF, Truong O, Hsuan JJ, Williams TJ 1994a. Eotaxin: A potent eosinophil chemoattractant cytokine detected in a guinea-pig model of allergic airways inflammation. J Exp Med 179: 881887.

Jose PJ, Adcock IM, Griffiths-Johnson DA, Berkman N, Wells TNC, Williams TJ, Power CA 1994b. Eotaxin: Cloning of an eosinophil chemoattractant cytokine and increased mRNA expression in allergen-challenged guinea-pig lungs. Biochem Biophys Res Commun 205: 788-794.

Kay AB, Wardlaw AJ, Collins JV, Dunnette S, Gleich GJ 1986. Eosinophil and major basic protein in broncho alveolar lavage in asthma: Relationship to non-specific hyperreactivity. J Allergy Clin Immunol 77: 236

Kitaura M, Nakajima T, Imai T, Harada S, Combadiere C, Tiffany HL, Murphy PM, Yoshie O 1996. Molecular Cloning of Human Eotaxin, an Eosinophil- 
selective CC Chemokine, and Identification of a specific Eosinophil Eotaxin Receptor, CC Chemokine Receptor 3. J Biol Chem 271: 77257730 .

Lefort J, Nahori A, Ruffié C, Vargaftig BB, Pretolani M 1996. In vivo neutralisation of eosinophil-derived major basic protein inhibits antigen-induced bronchial hyperreactivity in sensitised guinea pigs. J Clin Invest 97: 1117-1121.

Li D, Wang D, Griffiths-Johnson DA, Well NC, Williams TJ, Jose PJ, Jeffery PK 1997. Eotaxin protein and gene expression in guinea pig lungs: Constitutive expression and upregulation after allergen challenge. Eur Respir J 10: 1946-1954.

Lilly CM, Nakamura H, Kesselman H, Nagler-Anderson C, Asano K, Garcia-Zepeda EA, Rothenberg ME, Drazen JM, Luster AD 1997. Expression of eotaxin by human lung epithelial cells. J Clin Invest 99: 1767-1773.

MacLean JA, Ownbey R, Luster AD 1996. T cell-dependent regulation of eotaxin in antigen-induced pulmonary eosinophilia. J Exp Med 184: 1461-1469.

Miller MD, Krangel MS 1992. Biology and biochemistry of the chemokines: a family of chemotactic and inflammatory cytokines. Crit Rev Immunol 12: 17-46.

Ponath PD, Qin S, Post TW, Wang J, Wu L, Gerard NP, Newman W, Gerard C, Mackay CR 1996a. Molecular cloning and characterization of a human eotaxin receptor expressed selectively on eosinophils. J Exp Med 183: 2437-2448.

Ponath PD, Qin S, Ringler DJ, Clark-Lewis I, Wang J, Kassam N, Smith H, Shi X, Gonzalo J, Newman W, Gutierrez-Ramos J, Mackay CR 1996b. Cloning of the human eosinophil chemoattractant, eotaxin. Expression, receptor binding and functional properties suggest a mechanism for the selective recruitment of eosinophils. J Clin Invest 97: 604-612.

Rabe KF, Munoz NM, Vita AJ, Morton BE, Magnussen
H, Leff AR 1994. Contraction of human bronchial smooth muscle caused by activated human eosinophils. Am J Physiol 267: L326-34.

Rothenberg ME, Luster AD, Lilly CM, Drazen JM, Leder $P$ 1995a. Constitutive and allergen-induced expression of eotaxin mRNA in the guinea pig lung. J Exp Med 181: 1211-1216.

Rothenberg ME, Luster AD, Leder P 1995b. Murine eotaxin: An eosinophil chemoattractant inducible in endothelial cells and in interleukin 4-induced tumor suppression. Proc Natl Acad Sci USA 92: 8960-8964.

Rothenberg ME, MacLean JA, Pearlman E, Luster AD, Leder P 1997. Targeted disruption of the chemokine eotaxin partially reduces antigen-induced tissue eosinophilia. J Exp Med 18: 1-6.

Schall TJ, Bacon KB 1994. Chemokines, leukocyte trafficking and inflammation. Curr Opin Immunol 6: 865-873.

Springer TA 1994. Traffic signals for lymphocyte recirculation and leukocyte emigration: the multistep paradigm. Cell 76: 301-314.

Spry CJ 1971 Mechanisms of eosinophilia. Cell Tissue Kinet 4: 351-364.

Tenscher K, Metzner B, Schöpf E, Norgauer J, Czech W 1996. Recombinant human eotaxin induces oxygen radical production, $\mathrm{Ca}^{2+}$-mobilization, actin reorganization, and CD11b upregulation in human eosinophils via a pertussis toxin-sensitive heterotrimeric guanine nucleotide-binding protein. Blood 88: 3195-3199.

Venge P, Dahl R, Fredens K, Peterson CG 1988 Epithelial injury by human eosinophils. Am Rev Respir Dis 138: S54-7.

Wassom DL, Loegering DA, Solley GO, Moore SB, Schooley RT, Fauci AS, Gleich GJ 1981. Elevated serum levels of the eosinophil granule major basic protein in patients with eosinophilia. J Clin Invest 67: 651-661. 